\title{
Role of artificial intelligence and robotics to foster the touchless travel during a pandemic: A review and research agenda
}

\author{
Loveleen Gaur \& Anam Afaq \\ Amity International Business School, Amity University, Noida, India \\ Gurmeet Singh \\ School of Business and Management at The University of the South Pacific, Fiji \\ Yogesh K. Dwivedi \\ Emerging Markets Research Centre (EMaRC), School of Management \\ Swansea University Bay Campus, Swansea, Wales, UK
}

\begin{abstract}
Purpose The hospitality industry experienced an unanticipated challenge from the COVID-19 pandemic. However, research in this area is scarce. Accordingly, the present study unfolds a three-angled research agenda to intensify the knowledge advancement in the hospitality sector. It proposes a theoretical framework by extending the Protection Motivation Theory (PMT) to explain the guest's intent to adopt artificial intelligence (AI) and robotics as a protective measure in reaction to COVID-19.

Design/methodology/approach The research is centered on outlining the pertinent literature on hospitality management practices and the guest's transformed behavior during the current crisis. This study intends to identify a research agenda based on investigating hospitality service trends in today's changing times.

Findings The article sets out a research agenda that includes three dimensions (Artificial Intelligence \& robotics), (cleanliness \& sanitation), and (healthcare and wellness). This study's findings suggest that AI and robotics may bring out definite research directions at the connection of health crisis and hospitality management, taking into account the COVID-19 crisis.

Practical Implications The suggested research areas are anticipated to propel the knowledge base and help the hospitality industry retrieve the COVID-19 crisis through digital transformation. AI and robotics are at the cusp of invaluable advancement that can revive the hotels while re-establish guests' confidence in safe hotel practices. The proposed research areas are likely to impart pragmatic lessons to the hospitality industry to fight against disruptive situations.

Originality This article stands out to be pioneer research that incorporated AI and robotics to expand the PMT and highlights how behavioral choices during emergencies can bring technological revolution.
\end{abstract}

Keywords Artificial intelligence and robotics, COVID-19 pandemic, cleanliness and sanitation, Healthcare and wellness, Hospitality 


\section{Introduction}

The COVID-19 crisis has compelled the implementation of travel policies that have badly affected the global economy, significantly impacting the fields of travel, tourism, and hospitality (Pillai et al., 2021). According to the World Economic Forum (2020) (COVID Action Platform), nearly 100 million tourism and hospitality jobs are in jeopardy due to the pandemic's effects. These sectors are fighting to survive, let alone thrive. Travel and tourism have a symbiotic relationship with the hotel industry, and therefore the collapse of traveling on the outbreak of COVID-19 hindered the tourism and hospitality-related businesses. Hotels are particularly susceptible to decreased tourism and travel in parallel with the decline in economic affairs (Shin and Kang, 2020). As events worldwide got dropped or delayed, hotel bookings plunged, giving the hoteliers a tough time. For instance, revenue at Marriot hotels dropped by almost 90\% in Greater China in February 2020 and 25\% in different Asia Pacific regions (Jiang and Wen, 2020). It is anticipated that revenue in the U.S., Europe, and Asia will further continue to drop as holiday and business trips are mainly postponed or dropped (Jiang and Wen, 2020).

Generally, COVID-19 follows unforeseen and undesirable events, giving significantly less time to organize. This unprecedented crisis also implies a shortage of time for planning, and the customary response strategies are deficient (Sharma et al., 2020). Previous hospitality and tourism researches on a crisis like SARS, Ebola, and Influenza pandemics (Novelli et al., 2018), provide comparable patterns to COVID-19 but on a very small scale. Although tourist behavior articles help analyze the current development, the safety perceptions of the guests and tourists during the crisis are not studied extensively (Zenker and Kock, 2020). Hygiene and cleanliness play a significant role in hotel operations after the previous health crisis. These have become more important after the SARS 2003 health crisis (Kim et al., 2005). However, the severity of COVID-19 has changed people's perceptions. Many people are unwilling to travel for leisure and avoid staying at hotels (Gursoy and Chi, 2020). Moreover, people's lifestyle change due to fear motivates them to be involved in health and wellness programs (Majeed and Ramkissoon, 2020). To recover from the pandemic, hospitality businesses need to bring significant changes in their operations. This involves the guests' health and safety, which can amplify guests' inclination to return to hotels (Gössling et al., 2020). COVID-19 is probably going to affect the research agenda on hospitality and management research substantially. With these exceptional threats suffered by the hospitality and tourism sector during COVID-19, researchers are required to formulate effective solutions to recover from the crisis.

Crises can give birth to high-tech innovations. Therefore in this current COVID-19 turmoil, the hotel sector should consider the possible advantages of AI and its applications like robotics in the industry setting (Zeng et al., 2020). Previously, hospitality scholars have been examining the applicability of various automation and advancements in service delivery for many years; however, most of those examinations have concentrated on adopting poor technology (Gursoy and Chi, 2020). The new developments in AI and service robots have led to the embracing AI-driven technology in service delivery (Belanche et al., 2020a). This pandemic can instigate the importance of this innovation for public wellbeing reasons. Therefore, it is significant to figure out what will make the guests return, which requires immense research efforts. This discussion puts across the following gaps. (1) The outbreak of COVID-19 brought enormous challenges for the hospitality and tourism industry. however, research on what measures can drive back the guests to the hospitality businesses is scarce. (2) There are poor customary response strategies on the outbreak of COVID-19. (3) Cleanliness and health wellbeing are critical to hospitality and tourism operations. However, literature in this area is limited in number. (4) Technology integration into hospitality operations like AI and robotics during the current crisis is under-researched and requires extensive investigation. 
In view of the literature on the impact of an earlier health crisis like SARS in 2003 and the current crisis faced by the hoteliers caused by the outbreak of COVID-19, along with these identified gaps, the current article presents particular areas to present a meaningful vision to the academicians and practitioners to explore hotel management practices post COVID-19. The present research focuses on AI and robotics as a critical theme for the hospitality industry. It highlights the protective measures about the technological advancements in response to the COVID-19 health threats and details the necessity to adopt AI and robotics. While projecting the hotel industry's revival after covid-19, health and cleanliness should be the prime focus. Therefore, there is a need to examine how hotel service providers can team up with AI-driven robotics to enhance cleanliness and hygiene goals. The hospitality industry is now expected to make significant changes in its operations to ensure hotel guests' and employees' health and safety and reinforce customers' willingness to patronize the operations (Gössling et al., 2020). This pandemic is likely to have an unprecedented challenge for the hospitality industry, and scholars and experts are anticipated to develop solutions for the industry.

Considering the above aspects, the article discusses the possible effect of COVID-19 on the hospitality sector and undertakes two objectives. (RQ1) How the research intent provided from three dimensions: (AI and robotics), (Cleanliness and sanitation) and (Healthcare and wellness) will foster research and knowledge development in the hospitality sector. (RQ2) How will the proposed theoretical framework aid the guest's intent to adopt artificial intelligence and robotics as a protective measure for service delivery in response to the COVID-19 pandemic. The rest of the article is systematized as follows: Section 2 details the review of the literature. Section 3 comprises the methodology followed by the results depicted in section 4. Section 5 presents the future research agenda. Section 6 includes the conclusions, theoretical and practical implications, and limitations, and future research.

\section{Review of Literature}

\subsection{Review of global hospitality industry and disruptions}

The hospitality and tourism industry is susceptible to threats and global crises. COVID19 has all the earmarks of being another worldwide disaster like the 1918 Spanish influenza, particularly in the hospitality and tourism industry (Foroudi et al., 2020). A similar scenario appeared in 2003 due to the outbreak of SARS that caused a massive decline in GDP amounting to $\$ 20$ billion in China, Singapore, Hong Kong, Vietnam, and the Far East, witnessing a drop of $70 \%$ in tourism flow (McKercher and Chon, 2004). The present state of this pandemic is full of uncertainties, and its effects are much more severe than the previous pandemics (Gössling et al., 2020). The fear and shock caused due to the pandemic have resulted in negative perception and ambiguity for hospitality and tourism destinations (Foroudi et al., 2020). During the Ebola 2014 epidemic, hospitality and tourism were severely affected due to travel restrictions. People were not ready to travel to Africa's regions free from infection (Mizrachi and Fuchs, 2016). Therefore, during the global disaster and worldwide travel restrictions and quarantine, the hospitality industry experiences severe implications. As the hotel industry is susceptible to risks caused due to unforeseen blows like terrorist attacks, epidemics, and natural disasters, hoteliers need to take measures to deal with such a crisis. Table 1 lists some of the hoteliers' measures from different countries for facing the earlier crisis.

Table 1: Measures taken by the hoteliers during an earlier crisis

\begin{tabular}{|l|l|}
\hline Citation & $\begin{array}{l}\text { Measures taken by the hoteliers during } \\
\text { the earlier crisis }\end{array}$ \\
\hline Chan and Lam, 2013 & $\begin{array}{l}\text { In Hong Kong, the hoteliers carried robust } \\
\text { security by advancing the closed-circuit }\end{array}$ \\
\hline
\end{tabular}




\begin{tabular}{|l|l|}
\hline Kim et al., 2005 & $\begin{array}{l}\text { television systems and heightening security } \\
\text { training for the staff post } 9 / 11 \text { attacks. }\end{array}$ \\
\hline Nguyen et al., 2017 & $\begin{array}{l}\text { After the SARS crisis, the Korean hotel } \\
\text { industry incorporated new cleanliness } \\
\text { training regarding health education to their } \\
\text { employees. }\end{array}$ \\
\hline & $\begin{array}{l}\text { After the destruction brought about by the } \\
\text { Great East Japan Earthquake and Tsunami in } \\
\text { 2011, the hotels at the coastline in japan } \\
\text { offered shelter to the refugees }\end{array}$ \\
\hline
\end{tabular}

\subsection{Review of previous theories on disruptions in hospitality and tourism literature}

Theories from different fields have given insights into disaster and crisis management literature. From the tourism and hospitality literature, generally, researchers are inspired by management-related theories. For instance, Nguyen et al. (2017) applied the collaborative planning theory to examine the hotel stakeholder's perception and setbacks of collaboration. Few, Sociopsychological theories in hospitality and tourism were also applied in the context of crisis and disaster. For example, Wang and Wu (2018) adopted the theory of planned behavior to develop an iceberg model that depicts the causes of implicit beliefs and psychological factors on crisis planning and provides actions focusing on cultural diversity.

Moreover, interdisciplinary theories are also previously implemented. Brown et al. (2017) formulated a disaster management framework of natural, human, physical, economic, social, and cultural capital by applying the adaptive system theory. On the other hand, Ritchie (2008) adopted the chaos theory analyzing disaster management in tourism. The United Nations (2004) designed a framework for disaster risk reduction. Its key factors were knowledge development, early warning, risk factors, risk assessment, and recovery measures, regardless of the models and frameworks mentioned above. A new framework is required because the existing frameworks are not aligned with the health-related disaster and do not incorporate technological advancements into the theories.

\subsection{Theoretical Foundation: Protection Motivation Theory (PMT)}

As many people worldwide are exposed to this deadly COVID-19 disease, comprehending this risk will be a motivating factor for the individuals to adapt their behavior towards a more protective and safer medium of stay at the hotels. Few health behavior models like protection motivation theory (Rogers, 1975) and the theory of planned behavior (Ajzen, 2011) presents frameworks for understanding behavioral choices during pandemics. However, theories like the technology acceptance model, theory of planned behavior, and Chaos theory are insufficient to gauge guests' behavioral change towards adopting AI and robotics when confronted with a health threat.

This paper adopts PMT as a theoretical foundation to develop a framework for the hospitality industry. The framework incorporates the components of PMT formed by Ronald Rogers in the year 1975 that describes how people get motivated to change in a self-protective way in the vicinity of a perceived health threat. As per PMT, the fear appeal would give rise to the cognitive mediating process, which will trigger the protection motivation. Severity, vulnerability, response effectiveness, and self-efficacy can give rise to fear appeal among hotel guests, leading to adopt technologies like AI and robotics as a protective response to fight against the global pandemic. The fear appeal persuades the individuals to adopt techniques that can minimize the human touch. Touchless options like a contactless fingerprint, face recognition, contactless data entry can reduce the chances of spreading the virus. (Park, 2020). Figure 1 depicts the level of fear among individuals due to the outbreak of COVID-19. 


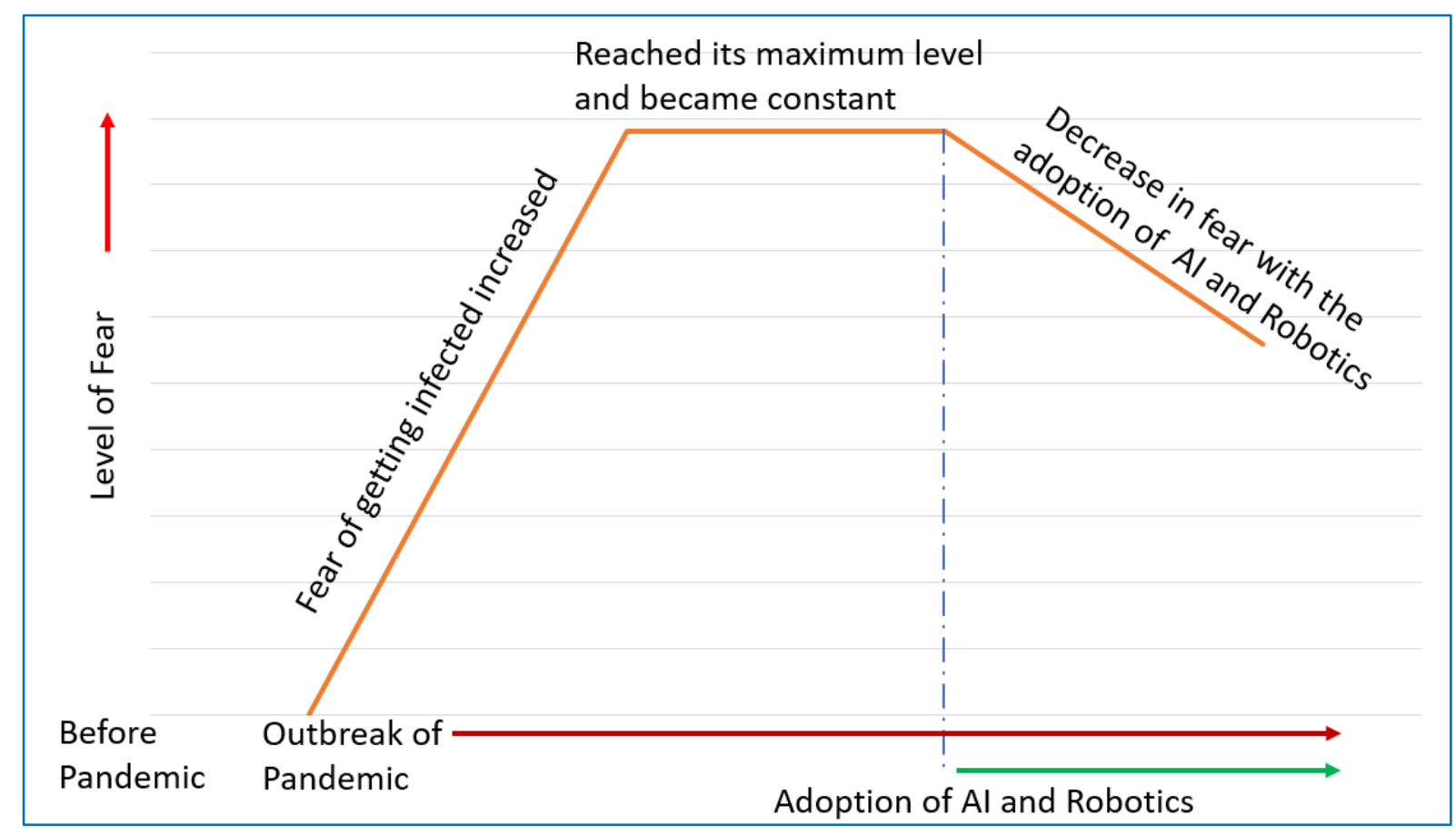

Figure 1: Graph depicting the level of fear among the hotel guests.

\subsection{Digital areas of transformation in the hospitality industry}

To begin with, the ongoing situation of the COVID-19 pandemic has given a lot of scope to scholars to intensify their knowledge towards AI and robotics and augment the literature in this area (Dwivedi et al., 2021; Huang and Rust, 2020). As COVID-19 is profoundly infectious (Chan et al., 2020), it is vital to follow physical distancing. Therefore, it can be said this is the right time for hoteliers to fasten the adoption of AI and robotics into the hospitality industry. Throughout the world, the hotel service scenario is taking a shift towards AI and robotics (Huang and Rust, 2020). Gradually hospitality firms have started introducing robots for providing frontline services to their guests (Belanche et al., 2020b). These frontline robots will enhance service experience and reduce the hospitality firms' operational costs (Belanche et al., 2020c).

AI is bringing revolution for the businesses by impacting trade and management practices in different sectors that provide growingly sustainable and competitive products and services (Di Vaio et al., 2020b). Previous studies have discussed the role of AI and robotics in hotels from varied points. For instance, Kuo et al. (2017) stated that service automation with service robots' could boost hotel competitiveness. These service robots are viewed as a future workmen in hotels who can assist the hotel staff. For example, in Japan, Henn-na Hotel, which is recognized as the first robot-working hotel by Guinness World Records, uses robots instead of human staff at the front desk, housekeeping, butler, and room services (Choi et al., 2020). Table 2 highlights the benefits of adopting AI and robotics in the hospitality industry stated by different authors.

Table 2: Role of AI and Robotics in service automation in hotels

\begin{tabular}{|l|l|l|}
\hline Citation & Role & Benefits \\
\hline de Kervenoael et al., 2020 & Novelty can trigger sales & $\begin{array}{l}\text { The novelty of seeing robots } \\
\text { delivering food and drinks can } \\
\text { trigger excitement which may }\end{array}$ \\
\hline
\end{tabular}




\begin{tabular}{|l|l|l|}
\hline & $\begin{array}{l}\text { Image of an innovative } \\
\text { company }\end{array}$ & $\begin{array}{l}\text { lead to more room service } \\
\text { orders. } \\
\text { A positive word of mouth can be } \\
\text { generated for the company by } \\
\text { using hi-tech technology for } \\
\text { serving the customers. }\end{array}$ \\
\hline Ivanov and Webster, 2019 & Enhancing the employees & $\begin{array}{l}\text { Robots can act as technological } \\
\text { extensions and tools for the } \\
\text { employees and can perform } \\
\text { repetitive jobs. }\end{array}$ \\
\hline Huang and Rust, 2020 & Enhancing service quality & $\begin{array}{l}\text { It can enhance the service } \\
\text { delivery process through new } \\
\text { interactive and appealing service } \\
\text { delivery methods and engaging } \\
\text { and communicating with the } \\
\text { customers. }\end{array}$ \\
\hline Kuo et al., 2017 & Saves employees time from \\
performing repetitive tasks & $\begin{array}{l}\text { Employees can focus on more } \\
\text { inventive and revenue- } \\
\text { generating exercises by saving } \\
\text { time from performing tedious } \\
\text { and repetitive tasks. }\end{array}$ \\
\hline
\end{tabular}

Secondly, the significance of cleanliness has significantly increased after the COVID19 pandemic, as this disease can widely spread by contacting the surfaces defiled with the virus (WHO, 2020). Considering this, few branded hotels like Marriott, Hyatt, and Hilton have already adopted technology for minimizing interactions between the guests and the employees. They have introduced a robot cleaning system, mobile check-In facilities, and kiosk check-in machines for the hotel guests. They have modified their cleaning and disinfection practices and upgraded to improved disinfection procedures like electrostatic sprayers and ultraviolet-light technology (Sharma et al., 2021). The cleanliness of rooms and restrooms in the hotels is a central aspect of a hotel's reputation. Numerous studies have considered cleanliness and hygiene a key determinant when choosing a hotel (Zemke et al., 2015). However, the researchers never discussed the cleanliness of specific areas and corners in the hotel (Park et al., 2019).

Therefore, our current study suggests that researchers need to move beyond the regular perspectives on the antecedents of hygiene and cleanliness in this sector and deeply dig into the guests' view of cleaning and disinfection measures like cleaning of key cards, TV remotes, surfaces that receive frequent human contact possess a higher chance of getting contaminated through touch and can be a medium to transmit infectious diseases like COVID-19 (Chen et al., 2020). Third, COVID-19 brought massive changes in people's lifestyles concerning their health (Wang et al., 2020). This increasing wellbeing and health trend can provide many opportunities to the hoteliers to attract customers by promoting intensely relaxing and wellnessfocused programs like balanced diet programs, preventive healthcare programs, fasting, detoxing programs, etc. These programs focus on holidays in wellness will reduce the stress and anxiety among the guests. As stated by Majeed and Ramkissoon (2020), in the future, the provision of wellness services will be essential because guest's priority will take a move towards health-related tourism post-COVID-19.

\section{Methodology}


Our methodology utilized a qualitative approach concentrating on the content of AIdriven technologies that provide contactless services, cleanliness, and safety to hotel guests. As this topic is recent, the spectrum of research resources also included pertinent news articles and reports. The insights from the book by Hall (2012) assisted a lot in improving the structure of the article. Further, the review of the IMRAD format assisted in organizing the main ideas and critical elements in the article (Day, 1989). We only considered articles in the English language in journals having impact factor 1 and above. The impact factor criteria were open for both options cite score as well as SJR of the journals. We performed a comprehensive literature search in the Google Scholar and Scopus databases. Choosing Scopus was mainly due to its extensive coverage of management studies as a research field (Martín-Martín et al., 2018). Google Scholar is a revolutionist in the information market and was preferred compared to the conventional databases, as it indexes data from the academic web.

To address the research questions, we referred to the PRISMA guidelines. Our database undertook a manual search on Google Scholar and Scopus, checking references of other pertinent academic journals. The initial search resulted in listing 800 records. Next, we removed the duplicate articles and were left with 782 records. After that, a formal screening process was carried. The inclusion criteria embodied all conceptual, empirical, and qualitative articles that revolved around AI and robotics and health crises. This left us with 450 articles. We excluded all the articles that discussed the architecture and design of AI-driven technologies. Next, specifically, more articles were extracted from few journals as compared to others since they are known to invite publications of empirical and theoretical nature on topics associated with AI, robotics, digital transformation, service automation, health/ hygiene, epidemics in the hospitality, tourism and other service industry.

We then utilized various keywords differently, combined among them and following our research questions. Notably, we combined "Conceptual frameworks" and "Artificial Intelligence," "Robotics" and "contactless services," "social distancing." Next, from time to time, these keywords were combined with other keywords: "COVID-19", "Wellness," "Healthcare," "Protection Motivation," "Cleanliness," "Travel," "Robots," "Pandemic." The secondary sources which did not have free access and posters were also excluded from the database. Next, we spotted the relevant articles and analyzed all the documents. To remove the chances of bias, all authors independently read the title, abstracts, and conclusion of the identified records. This led to the inclusion of only 149 records on the consensus of all the authors. Further, these records were thoroughly analyzed to focus on our research's integral aspects. The articles that were not enough relating to the research questions were secluded from the database with mutual agreement. All authors compared their results from the analysis and further wrote different sections of the article. The methods adopted in prior review and research agenda papers (Di Vaio et al., 2020d) assisted in forming our methodology approach. Finally, we had 61 citations for the article. Figure 2 depicts the methodology approach. 


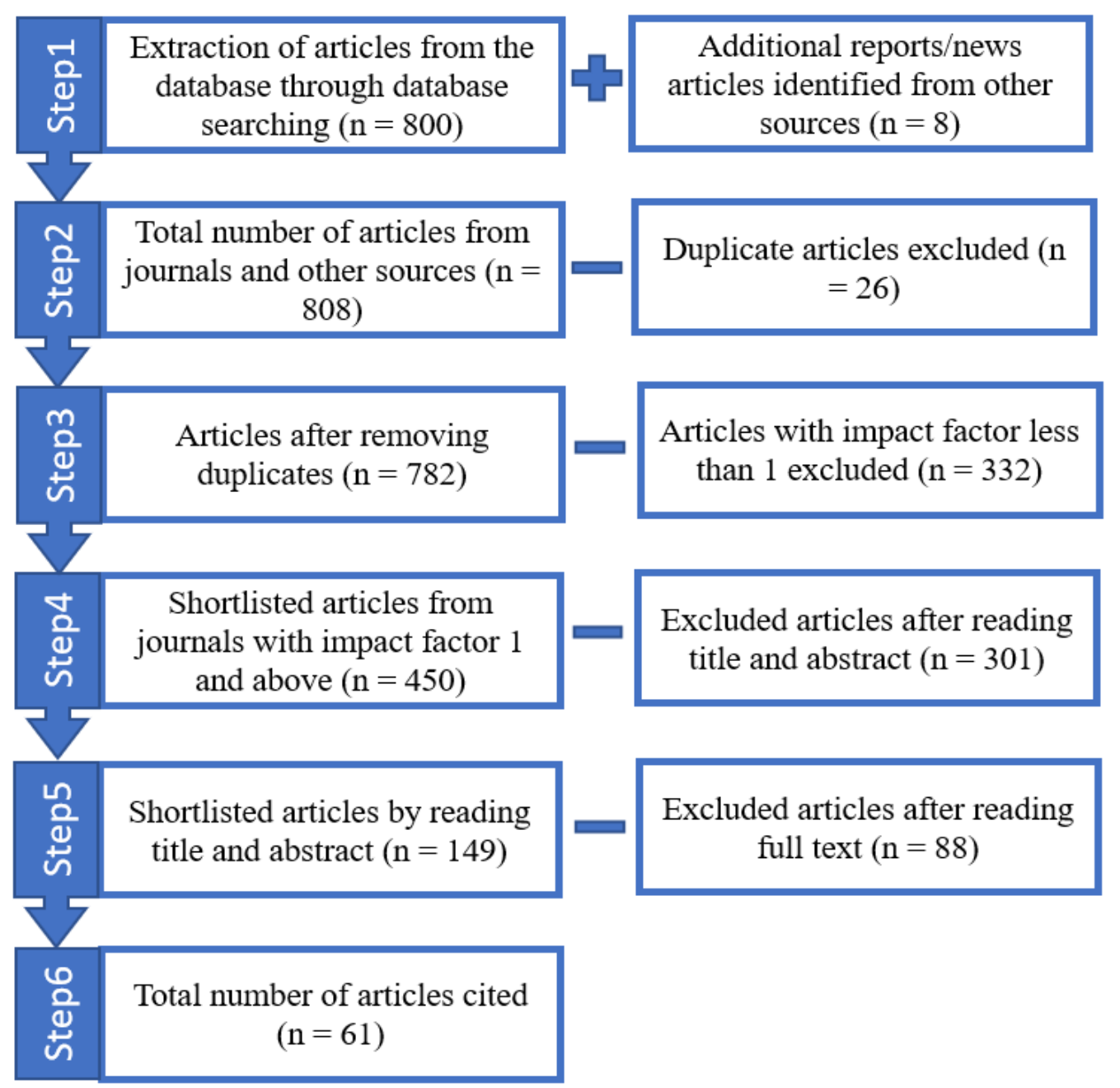

Figure 2: Methodology Approach

\section{Results}

All included articles are from journals having impact factor 1 and above (cite score or SJR). The impact factor table 3 summarises the number of articles, chapters, and reports cited in the current article.

Table 3: Impact Factor table

\begin{tabular}{|c|c|c|}
\hline \multicolumn{2}{|c|}{ Study Type } & Count \\
\hline \multicolumn{2}{|c|}{ Papers with Impact Factor more than 1} & 55 \\
\hline \multirow{7}{*}{$\begin{array}{l}\text { Impact } \\
\text { Factor } \\
\text { Range }\end{array}$} & 1 to 2 & 5 \\
\hline & 2 to 3 & 9 \\
\hline & 3 to 4 & 3 \\
\hline & 4 to 5 & 19 \\
\hline & 5 to 6 & 9 \\
\hline & 7 to 8 & 5 \\
\hline & more than 8 & 5 \\
\hline \multicolumn{2}{|c|}{ Chapters from books } & 2 \\
\hline \multicolumn{2}{|c|}{ News Article } & 1 \\
\hline \multicolumn{2}{|c|}{ Reports } & 3 \\
\hline \multicolumn{2}{|c|}{ Total } & 61 \\
\hline
\end{tabular}


As the articles are cited from different journals, the below-mentioned figure 3 illustrates the journals' names and the number of articles cited from those journals.

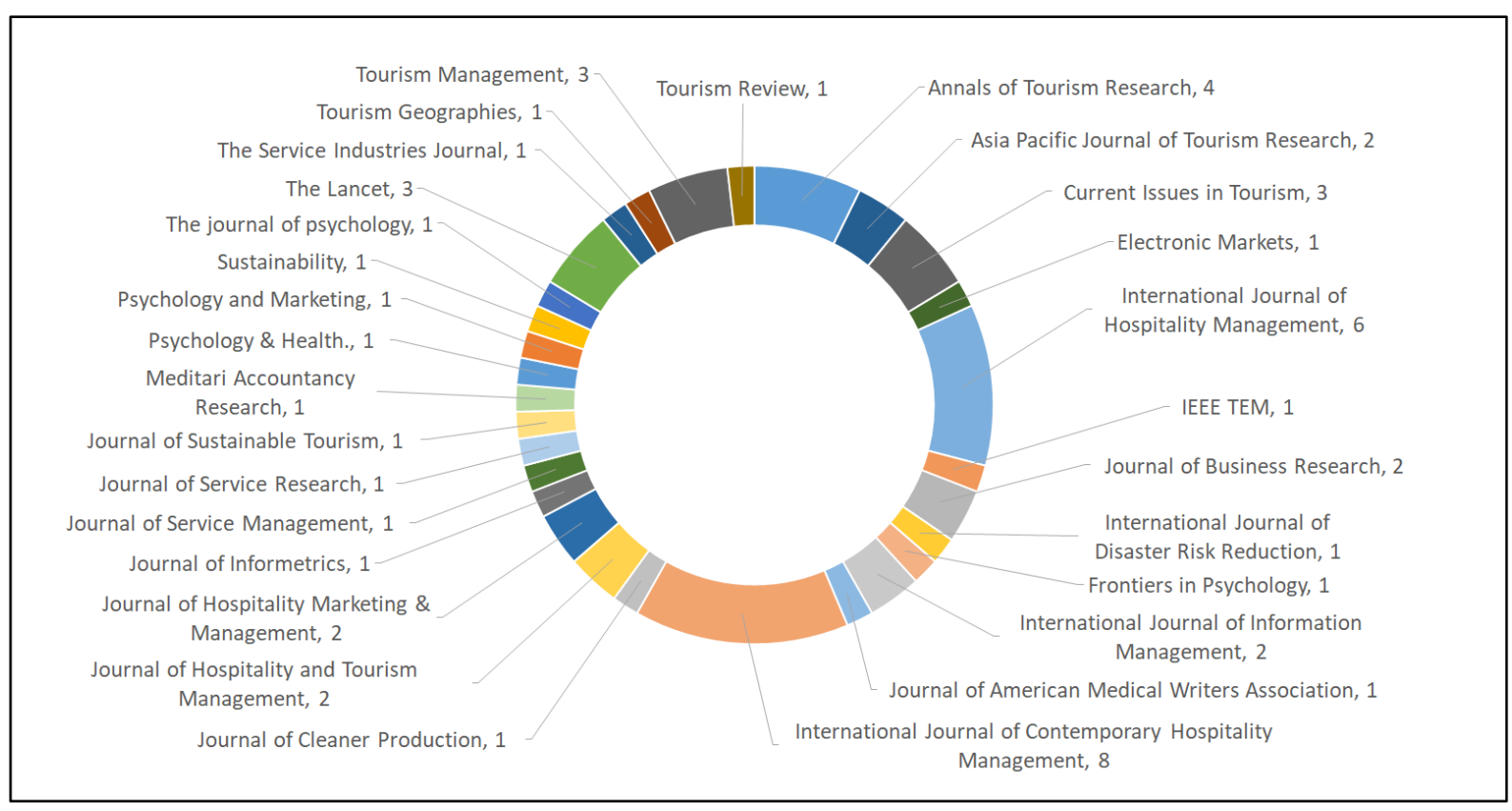

Figure 3: Publication source of included articles.

To give a more descriptive presentation to the manuscript, details of the broad topics covered in different journals and insights about the topics covered in all articles are depicted in table 4.

Table 4: Topics Covered in Journals and Articles

\begin{tabular}{|l|l|}
\hline Journal & The broad range of topics covered in the Journals \\
\hline Annals of Tourism Research & Business Tourism, Leisure and Hospitality management. \\
\hline $\begin{array}{l}\text { Asia Pacific Journal of } \\
\text { Tourism Research }\end{array}$ & $\begin{array}{l}\text { Technologies to Planning and Development, Hospitality } \\
\text { Management, Issues in tourism }\end{array}$ \\
\hline Current Issues in Tourism & $\begin{array}{l}\text { Disciplinary and interdisciplinary range of critical } \\
\text { approaches available to the study of tourism }\end{array}$ \\
\hline Electronic Markets & $\begin{array}{l}\text { New forms of social change, electronic "market" issues, } \\
\text { information technologies. }\end{array}$ \\
\hline Frontiers in Psychology & $\begin{array}{l}\text { Cognition, Comparative Psychology, Cultural } \\
\text { Psychology. }\end{array}$ \\
\hline $\begin{array}{l}\text { IEEE Transactions on } \\
\text { Engineering Management. }\end{array}$ & Technological innovation, technology assessment \\
\hline $\begin{array}{l}\text { International Journal of } \\
\text { Contemporary Hospitality } \\
\text { Management }\end{array}$ & $\begin{array}{l}\text { Operations, marketing, finance and personnel hospitality, } \\
\text { Hospitality management strategies }\end{array}$ \\
\hline $\begin{array}{l}\text { International Journal of } \\
\text { Disaster Risk Reduction }\end{array}$ & $\begin{array}{l}\text { Environmental and social sciences; technological and } \\
\text { intentional disaster }\end{array}$ \\
\hline
\end{tabular}




\begin{tabular}{|c|c|}
\hline $\begin{array}{l}\text { International Journal of } \\
\text { Hospitality Management }\end{array}$ & $\begin{array}{l}\text { Human resources management; consumer; business } \\
\text { forecasting and applied economics; technological } \\
\text { developments. }\end{array}$ \\
\hline $\begin{array}{l}\text { International Journal of } \\
\text { Information Management }\end{array}$ & $\begin{array}{l}\text { Business intelligence, knowledge management, } \\
\text { information design and delivery, information for health } \\
\text { care }\end{array}$ \\
\hline $\begin{array}{l}\text { Journal of American Medical } \\
\text { Writers Association }\end{array}$ & $\begin{array}{l}\text { Medical Advertising, Publication ethics, regulatory } \\
\text { writing }\end{array}$ \\
\hline Journal of Business Research & $\begin{array}{l}\text { Buyer behavior, organizational theory, risk and insurance, } \\
\text { international business }\end{array}$ \\
\hline Journal of Cleaner Production & $\begin{array}{l}\text { Environment and sustainability assessment, Corporate } \\
\text { sustainability }\end{array}$ \\
\hline $\begin{array}{l}\text { Journal of Hospitality and } \\
\text { Tourism Management }\end{array}$ & $\begin{array}{l}\text { Consumer Behavior, HRM, Guests Experiences and } \\
\text { expectations }\end{array}$ \\
\hline $\begin{array}{l}\text { Journal of Hospitality } \\
\text { Marketing \& Management }\end{array}$ & $\begin{array}{l}\text { Hospitality marketing, branding, ethical concerns, } \\
\text { reputation management }\end{array}$ \\
\hline Journal of Informetrics & Topics in bibliometrics, scientometrics, webometrics \\
\hline $\begin{array}{l}\text { Journal of Service } \\
\text { Management }\end{array}$ & Service strategy, excellence, and innovation \\
\hline Journal of Service Research & Service marketing, global issues, and quality, E-Service \\
\hline $\begin{array}{l}\text { Journal of Sustainable } \\
\text { Tourism }\end{array}$ & Economic, Social, Cultural, Political aspects of tourism \\
\hline $\begin{array}{l}\text { Meditari Accountancy } \\
\text { Research. }\end{array}$ & $\begin{array}{l}\text { Social impacts of accounting, sustainability and risk } \\
\text { management }\end{array}$ \\
\hline Psychology \& Health. & $\begin{array}{l}\text { Psychological and psychosocial attributes of physical } \\
\text { illnesses. }\end{array}$ \\
\hline Psychology and Marketing & Psychological theories and techniques to marketing \\
\hline Sustainability & $\begin{array}{l}\text { Sustainable tourism, Waste technology, disaster } \\
\text { management }\end{array}$ \\
\hline The journal of psychology & Psychology of health and illness \\
\hline The Lancet & Digital Health, Infectious Diseases, Public Health \\
\hline Tourism Management & Tourism regional tourism, ecotourism \\
\hline \begin{tabular}{|l|l} 
Tourism Review & \\
\end{tabular} & Business models, mobility in tourism, sustainable tourism \\
\hline \multicolumn{2}{|c|}{ A broad overview of the topics covered in the Articles reviewed } \\
\hline \multicolumn{2}{|c|}{$\begin{array}{ll}\checkmark & \text { The collapse of global tourism and hospitality businesses. } \\
\checkmark & \text { Technological innovations in the hospitality industry post covid- } \\
\checkmark & \text { Disaster planning/crisis management } \\
\checkmark & \text { Previous health crisis/ epidemics } \\
\checkmark & \text { Adoption of AI-driven technology } \\
\checkmark & \text { Service robots in hospitality and tourism } \\
\checkmark & \text { Covid-19 and changed guest and travel behavior } \\
\checkmark & \text { Health, wellness, and tourism } \\
\checkmark & \text { cleanliness in hotels } \\
\checkmark & \text { AI and sustainability of hotels } \\
\checkmark & \text { Hotel healthcare practices } \\
\checkmark & \text { Service robots and guest's experiences } \\
\checkmark & \text { Protection motivation among travelers } \\
\checkmark & \text { Employees and service automation } \\
\checkmark & \text { Hospitality and tourism recovery strategies }\end{array}$} \\
\hline
\end{tabular}


To generate a better picture of the included articles, a map depicting the co-occurrence of terms in the title and abstract is illustrated in Figure 4. The colorful nodes and the specific terms are associated with each other. The size of the nodes depicts the frequency of the term that is occurred. While the link between two nodes represents the co-occurrence of the terms. The figure illustrates that the frequently co-occurring terms create clusters and appear closer to the same color. A first look at this map of the co-occurrence terms shows the central cluster (grey color) with terms including artificial intelligence, service robots, COVID-19, travel, health, hospitality, tourism, crisis, and cleanliness.

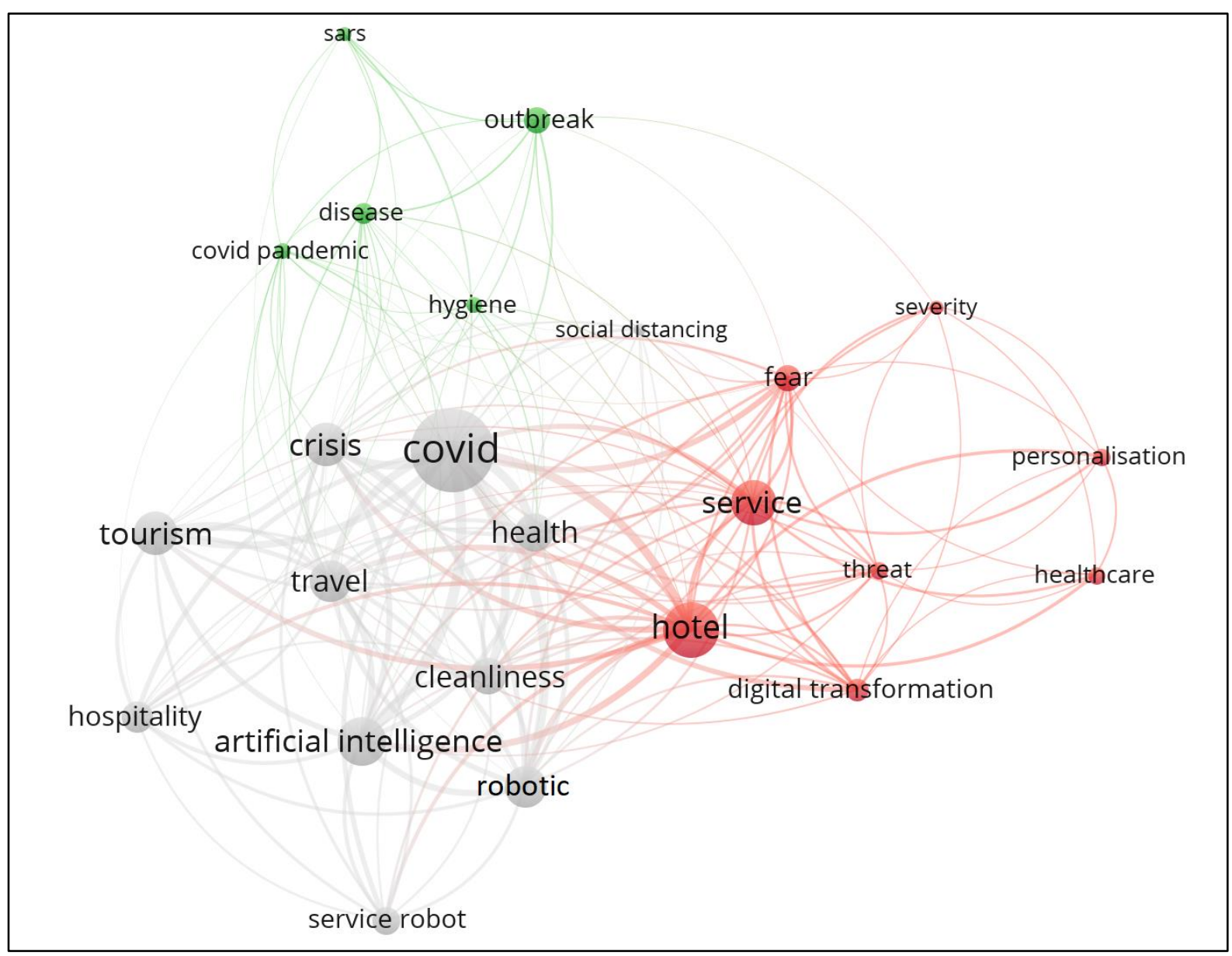

Figure 4: Map of the co-occurrence terms

\subsection{Findings from the articles}

The analysis of the articles has highlighted the massive change in guests' behaviors due to the outbreak of the pandemic. Scholars have evidenced that the downfall in the hotel businesses and collapse of global tourism needs immediate attention. There is an urgent need for the hospitality and tourism sectors to devise recovery strategies. 25 articles out of the total reviewed articles specifically emphasize the need to adopt AI and robotics in the hospitality and tourism sector in the future. The topics covered in the articles like the trust in services of robots, new technological innovations in hotels, Robots for the rescue of guests during Covid, AI-driven technologies to reduce health risk among guests, etc. depict the inclination of the researchers towards the adoption of AI and robotics (Mariani and Perez, 2020). As per some 
scholars, AI will also balance the unavailability of the human workforce during the Covid-19 crisis.

Also, the findings of few articles on AI and robotics detail how the adoption of service robots in hospitality and tourism can reduce operational costs and enhance services. Therefore, the adoption of AI and robotics appears as a notable change for hospitality practitioners. Indeed, technological innovations can reduce health risks among guests. These findings show that technical measures can help minimize the transmission of COVID-19 and attract guests. For instance, few articles state that service robots can act as a technological shield between the hotel guests and employees, reducing the chances of infection (Seyitoğlu and Ivanov, 2020). Consequently, new strategies have to be adopted and redesigned around AI and robotics to deal with the effects of Covid-19. Scholars suggested the need to modify international strategies after this global crisis and insist on the relative importance of safety facilities at the hotels (Chen et al., 2020).

Some scholars emphasized the importance of disaster planning and suggested the hospitality and tourism companies develop effective policies. Scholars have identified in the articles about the changed guest's perception and behavior on the outbreak of Covid-19. Some articles state the growing demand for health and wellness tourism. This article also contributes to the previous studies on epidemics and crisis management in the hospitality and tourism industry. The research supports the previous studies that state that crisis brings changes in customers' mindsets and inclines them towards the use of technology. Previous epidemic studies have suggested measures for preparedness during a crisis in the hospitality and tourism industry, but these methods lacked devoted technology. Thus, the current article extends the literature on pandemic preparedness in the hospitality and tourism sectors.

\subsection{Comparative analysis of previous studies on the hospitality and tourism sector after the outbreak of COVID-19}

During this face of COVID-19, various studies are conducted in the hospitality and tourism industry. The analysis of research into hospitality and tourism literature during the ongoing COVID-19 crisis can help identify the findings of all relevant articles on this sector. The results of various studies are as follows: Gössling et al. (2020) compared COVID-19 with earlier pandemics and global crises and stated how COVID-19 could change tourism practices in the future. Baum and Hai (2020) conducted a real-time assessment of the impact of COVID19 and the threat to the right to participate in tourism and hospitality practices. They found that parts of Asia, North America, and Europe are facing enormous challenges. Wen et al. (2020) analyzed the changes in Chinese tourists' lifestyle during COVID-19 and found that tourists will now focus more on health and wellness tourism. Jones and Comfort (2020) gave insights on the change in the relationship between hospitality and sustainability on the outbreak of COVID-19. They found that this crisis can provide a vision for a more sustainable future.

Lai and Wong (2020) compared how the hotel practices were different during the initial stage of the crisis and the pandemic stage and highlighted strategies like pricing adopted by the hotels during these two stages. Im et al. (2021) analyzed 57 CEO letters published during the pandemic by the hospitality companies; the findings reveal that hospitality organizations primarily relied upon defensive approaches and powerful tactics during COVID-19. Baum et al. (2020) studied the immediate impact of COVID-19 on the hospitality workforce between April to June 2020 at three levels, macro, meso, and micro. The findings suggest that hospitality stakeholders, the industry, consumers, and the government, will revive the pandemic with a tremendous changed attitude for the hospitality workers. Garrido-Moreno et al. (2021) identified critical drivers for the recovery of the hotels using a survey method. He found that ways like digital marketing involving social media campaigns, discounted packages, and offers on social media can help win back customers' confidence. 


\section{Future research agenda}

The literature review sheds light on the growing necessity of AI and robotics in the hospitality industry, particularly during the COVID-19 crisis. Therefore, this article presents three research agenda that needs to be addressed to prepare the hospitality industry to face the changes that are certain to come due to outbreak of COVID-19 and based on the research agenda about AI and robotics, proposes a theoretical framework for the hospitality industry.

\subsection{AI and Robotics}

It is crucial to understand the guest's experiences and thoughts concerning the robots' contactless services (Di Vaio et al., 2020a). The areas to be addressed in the future can focus on developing robot-friendly hospitality measures, which could help provide adequate services. There are visibly many changes in the traveler's demand due to the outbreak of COVID-19 (Wen et al., 2020). Therefore, future research can inquire into the relevance of applying techniques like deep learning to personalize hotel services. Furthermore, researchers can explore how Big data and analytical AI can be utilized to pull down the individual choices in service preferences (Huang and Rust, 2020). Di Vaio et al. (2021) stated that digital transformation encourages information and proficient practices using big data. The hoteliers should harness big data's power for establishing their competitive advantage by providing personalized guest services (Mariani and Perez, 2020).

COVID-19 has developed fear in the customer's mind. It is essential to build trust during the current challenging time and show empathy towards the hotel guests (Jiang and Wen, 2020). Therefore, the researchers must investigate AI's role in delivering customer services in hotels. Considering the positive and negative prospects around AI in hotel services, researchers should evaluate the hotel's return on investment concerning the adoption of service robots. Further, it can be investigated that the adoption of service robots in hotels is limited to promotional stunts or fully utilized concerning their service performance. Apart from the stated research agendas, it is also essential to study the ethics involved in adopting AI and robotics in the hospitality industry.

As Huang and Rust (2020) stated, the increasing use of AI can replace human labor, leading to the absence of human employees at the hotels and a completely different service experience by the guests. However, the effects of service automation in hotels depend on how AI is implemented. For example, process automation that includes updating files (customer information) in the computer systems does not pose a big threat to the hotel staff (Ivanov and Webster, 2019). With these given trends in hospitality management practices, it is pivotal for future studies to explore how process automation and cognitive engagement can be used by the hotels to address the problems caused by COVID-19 and to examine the ways through which AI solutions can be applied for dealing with the challenges like COVID-19. Furthermore, future research should also focus on the following areas in robotics, as mentioned in table 5.

Table 5: Future directions towards the adoption of robotics in the hospitality industry

\section{Future directions towards the adoption of Robotics}

Affirmation and application towards robots' use by the distinctive categories and generations of hotel guests. As a general presumption, are older customers more hesitant to adopt service robots than young customers?

The adequate level of acceptance of robotization in the hospitality sector.

In what capacity should robots be designed to offer convenient services to the guests.

To what degree do youngsters give relevant possibilities to test and create service robots compared to older ones?

Do men and women desire diverse robot designs and features? 
Customers' propensity to trust and experience a sense of safety about service delivery by the hospitality industry's robots.

The role of customer culture in accepting the services offered by a service robot.

Operations and tasks in the hospitality services to show a positive attitude in accepting robotization.

Customer's preferment concerning the robots' appearance, narration, and distinct features essential for framing an optimistic opinion towards them.

\subsection{Cleanliness and Health}

Regarding the growing demand for hotel hygiene after the outbreak of COVID-19, future research can focus on how the cleanliness and sanitization procedures followed at the hotels can be used as a selling point for hoteliers in the future. A study by Zemke et al. (2015) stated that women of all ages and youngsters would preferably pay a higher amount of money for improved disinfection of the guestrooms. In light of their work, future researchers can study that "Are the hotel guests of different segments willing to pay a premium amount for better sanitization and disinfection facilities at the hotels." Also, as the advanced level of sanitization may require huge capital for equipment and technology, future research should consider the degree to which sanitization practices should be improved at the hotels.

In the specific circumstance of COVID-19, AI can be applied to perform cleaning and sanitization tasks (Jiang and Wen, 2020). de Kervenoael et al. (2020) found that visitors are inclined to use social robots in the travel and hospitality industry. (Zhong et al., 2020) experimented to determine the impact of service robots on hotel guests' purchasing behavior. The findings revealed that people who watched videos of hotel service robots had a higher booking intention than those who watched traditional service videos. Thus, it is noteworthy to inspect the impact of robots on clients' cordiality experience. Areas to consider in the future include cleaning and disinfection procedures at hotel properties that can be carried out by AIdriven robotics, and implications could be imparted to experts to enhance service robot design to improve customer relationship management. Another research direction in pandemics' particular setting is how the hotels can generate real-time data to create a prediction and alert system for infectious disease dependent on big data and AI as a team with computers and researchers.

\subsection{Healthcare and Wellness retreats}

Under Covid-19 conditions, it is desirable to examine further how the hoteliers can plan and design customized products to magnify their experience. In particular, researchers could think about how to constructively use the guests' social data and their consumption patterns like their visit to the hotel's fitness center, variety of food ordered, etc. (Mariani and Perez, 2020). Using predictive analytics by using the information of the guests can help the hoteliers design personalized health-related services. As of now, the mainstream focus of hotels will be on personalization, health, and wellness. Even though the term wellness may have various implications, giving a protected place for relaxation with personalization can reduce travelrelated anxiety and pull in the hotel guests smartly. As the hospitality industry plans for a comeback with greater strength, they should redesign the wellness programs to fulfill the new wellness-determined guests. Human wellbeing starts from the strength of nature. This pandemic has compelled people to recognize the power of nature. This crisis will give rise to environmentally sustainable tourism forms and promote harmony between humans and nature (Di Vaio and Varriale, 2020). Eco-friendly strategies and green practices can be a new norm for hotels to attract customers.

Future studies can investigate the guests' attitude towards adopting green hotel attributes and extending the literature. There is also a need to investigate the prospects for 
hospitality practitioners to work together with the guests to co-create green value. Furthermore, future studies should also examine how medical services with expert medical staff can provide better value to the hotel guests, increasing their occupancy rate post-COVID-19. For example, Le Bijou, a swiss hospitality company, provides quarantine-friendly facilities like automatic check-in and in-room medical facilities to its guests (Lastoe, 2020). Furthermore, it is relevant to explore the growing relationship between the hotel sector and the healthcare sector. The viability of converting hotels into quarantine centers during a crisis should be further explored with empirical data. Nguyen et al. (2017) studied the cooperation between the hotel sector and the local government to minimize disaster risk in the coastal areas. The findings revealed that hotels could play a significant role in providing shelter during such a crisis.

\subsection{Theoretical Framework for Hospitality Industry}

Amidst the review and research agenda, the study proposes a theoretical framework by extending the PMT to use AI and robotics in the hospitality industry during the COVID-19 crisis. This framework depicts how the threat appraisal and coping appraisal give way to protection motivation among the guests. Pre-COVID-19, there was a direct link between the (hotels \& guests). However, the disruptions caused by COVID-19 created a gap. Figure 5 depicts how the layer of protective measures in emerging technology can fill in this gap. The dropped guest volume can be increased, and the hotels with deserted hallways can get better. This proposed framework can give way to a new paradigm wherein the service providers can facilitate better services to their customers during and after the COVID-19 pandemic.

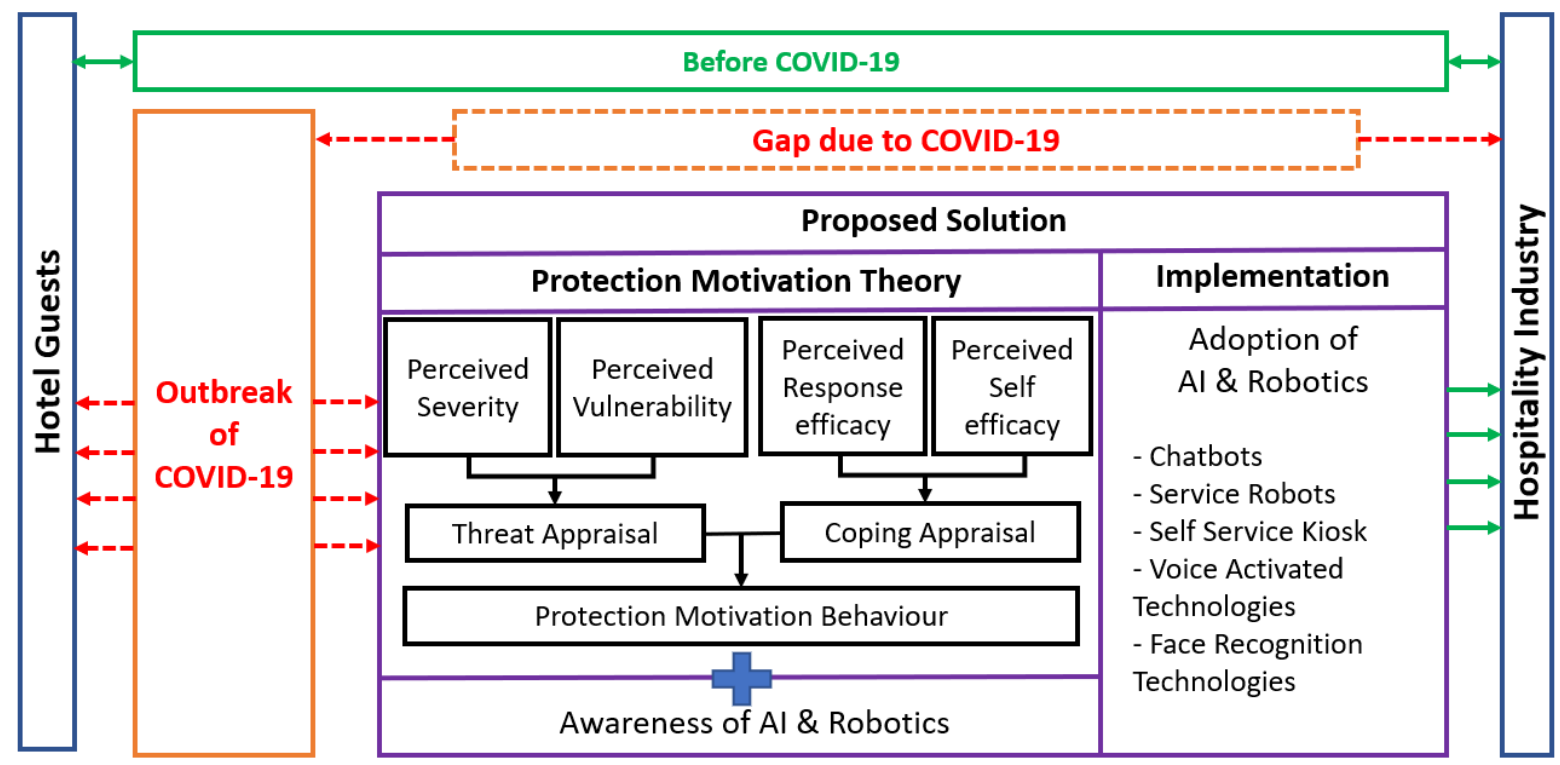

Figure 5: Theoretical Framework for Hospitality Industry

\section{Discussion and Conclusions}

\subsection{Conclusion}

The research agenda submitted in this article (AI and robotics) (cleanliness and sanitation) and (Health and Wellness) fosters research and knowledge development in the hospitality sector. As fearful guests are unwilling to stay or dine at hotels, it drastically affects their survival. Therefore, figuring out what measures can make the guests return requires extensive research. This article addresses this aspect by presenting the research agenda from three dimensions as stated above and proposes a theoretical framework incorporating AI and robotics as a protective measure for providing service delivery to rebuild the guest's confidence. 
Compelling strategies are required to boost guests' confidence and help hospitality businesses quickly recover from this crisis. The hotels' resilience and sustainability can be improved by addressing guest's growing concerns and converting adversity into opportunity. The past pandemics emphasized the importance of hygiene and cleanliness for the survival of hotels. As technology can help provide effective cleanliness measures during COVID-19, this study addresses AI and robotics' roles in giving guests contactless services. The article highlights that implementing AI and robotics as depicted in the theoretical framework can create a technological shield that can provide contactless services and provide a competitive advantage to the hotels during and post COVID-19. Furthermore, the emerging trends among guests like wellness and environmental conservation must be addressed.

\subsection{Theoretical Implications}

This study consists of several theoretical implications. First, this study contributed by extending the PMT and incorporating AI and robotics to develop a new framework for the hospitality industry. The study highlights how behavioral choices during emergencies can bring technological revolution and how hospitality practitioners can embrace these changes to recover from the pandemic. Second, while fear and uncertainty in guest's decision-making have been an essential topic of research, there is still a necessity for an orderly comprehension of how hospitality customers see health risks and how this impacts their choice of visiting a hotel. The current study filled this research gap by analyzing the notable effect of apparent health risk on guest's decision to visit hotels during the outbreak of COVID-19. Third, the study details that robots are an appropriate option for performing repetitive, routine, and dangerous jobs like cleaning and disinfection during pandemics. This will reduce the physical contact between the hotel staff and the guests and help minimize the spread of disease. Furthermore, employees can use their skills to perform tasks that require creativity.

\subsection{Practical Implications}

The COVID-19 pandemic has brought a massive change in the hospitality sector's working in terms of safety. Significantly, digital transformation will be the frontier in hospitality practices. In this context, the current study proposes useful, practical implications. First, hotels need to give assurance about the effectiveness of their safety measures by incorporating $\mathrm{AI}$ and robotics technologies to maintain social distancing. The focus should be on providing contactless services like self-check-in and check-out facilities, face recognition systems, cleaning robots, and digital key services. Adopting advanced technologies like electrostatic sprayers, germ-destroying robots, and ultraviolet light should be preferred. As the hotel facilities are shared with other customers, it is vital to disinfect the other high touch surfaces in the hotel properties apart from the rooms' disinfection.

Second, providing appropriate information to the guests regarding the hotels' risk reduction strategies will assure the guests of their safety, assisting them in the decision-making process. Accurate information provided to the customers by the company can affect customer's decision-making. Therefore, the hotels need to keep the hospitality customers informed about the hotels' strategies to protect their guests' health. Third, the outbreak of COVID-19 is bringing changes in the marketing strategies of the hoteliers. They need to move towards environmentally friendly ways of tourism. The hospitality practitioners should shift towards eco-friendly practices as demanded by the guests. Moreover, they should focus on wellbeing and health-related holiday programs for the guests.

\subsection{Limitations and Future Research}

The current article has limitations in the context of generalizability. The research is limited to the sectors of hospitality only, like hotels and restaurants. Another limitation is the analysis of the researched articles based on specific keywords to answer the research questions. As the authors have used particular keywords for the research process, there is a possibility that few items might be missed during screening. Further, this article did not consider ethical issues 
like data privacy while proposing the theoretical framework. However, the issues revolving around data security and privacy can be resolved using future AI technologies. For example, incorporating robust blockchain technologies can ensure data privacy and security (Di Vaio and Varriale, 2020c). In the future, scholars can explore the advantages of big data and other emerging techniques like text mining and image analytics. Future studies must consider utilizing big data and analytics concerning cleanliness and health practices in the hospitality context regarding the industry's ongoing technological revolution.

Apart from the research agenda discussed in the article, another critical area to explore is crisis management. As the hospitality sector is a noticeable victim of pandemics, the hospitality companies must prepare a contingency plan for such a crisis. Future researches should also explore how service industries and government agencies can form crisis management schemes. COVID-19 has disturbed the functioning and operations of global hospitality companies. Both practitioners and researchers should come together to analyze the impact of this crisis and improve industry practices. Empirical data from the industry could assist the researchers in making accurate predictions. To address the issues depicted in the article, future research could include different approaches like focus groups, In-depth interviews, mixed-method approach, etc. The authors anticipate that the research agenda detailed in this article will further elucidate pertinent topics of interest and stimulate further study.

\section{References}

Ajzen, I., 2011, "The theory of planned behaviour: Reactions and reflections", Psychology \& Health, Vol. 26 No. 9, pp.1113-1127.

Baum, T., \& Hai, N. T. T. (2020), "Hospitality, tourism, human rights and the impact of COVID-19”, International Journal of Contemporary Hospitality Management, Vol. 32 No. 7, pp.2397-2407.

Baum, T., Mooney, S. K., Robinson, R. N., \& Solnet, D. (2020), “COVID-19's impact on the hospitality workforce-new crisis or amplification of the norm?", International Journal of Contemporary Hospitality Management, Vol. 32 No. 9, pp.2813-2829.

Belanche, D., Casaló, L.V., Flavián, C. and Schepers, J., 2020a, "Service robot implementation: a theoretical framework and research agenda", The Service Industries Journal, Vol. 40 No. 3-4, pp.203-225.

Belanche, D., Casaló, L.V., Flavián, C. and Schepers, J., 2020b, "Robots or frontline employees? Exploring customers' attributions of responsibility and stability after service failure or success", Journal of Service Management, Vol. 31 No. 2, pp.267-289.

Belanche, D., Casaló, L. V., \& Flavián, C. (2020c), "Frontline robots in tourism and hospitality: service enhancement or cost reduction?", Electronic Markets, 1-16. doi: $10.1007 / \mathrm{s} 12525-020-00432-5$

Brown, N.A., Rovins, J.E., Feldmann-Jensen, S., Orchiston, C. and Johnston, D., 2017, "Exploring disaster resilience within the hotel sector: A systematic review of literature", International Journal of Disaster Risk Reduction, Vol. 22, pp.362-370.

Chan, E.S. and Lam, D. 2013, "Hotel safety and security systems: Bridging the gap between managers and guests", International Journal of Hospitality Management, Vol. 32, pp.202-216. 
Chan, J.F.W., Yuan, S., Kok, K.H., To, K.K.W., Chu, H., Yang, J., Xing, F., Liu, J., Yip, C.C.Y., Poon, R.W.S. and Tsoi, H.W. 2020, "A familial cluster of pneumonia associated with the 2019 novel coronavirus indicating person-to-person transmission: a study of a family cluster", The Lancet, Vol. 395 No. 10223, pp.514-523.

Chen, H., Huang, X., \& Li, Z. (2020), “A content analysis of Chinese news coverage on COVID-19 and tourism", Current Issues in Tourism, 1-8. doi: 10.1080/13683500.2020.1763269.

Chen, S., Yang, J., Yang, W., Wang, C. and Bärnighausen, T., 2020, “COVID-19 control in China during mass population movements at New Year", The Lancet, Vol. 395 No. 10226, pp.764-766.

Choi, Y., Choi, M., Oh, M. and Kim, S., 2020, "Service robots in hotels: understanding the service quality perceptions of human-robot interaction", Journal of Hospitality Marketing \& Management, Vol. 29 No. 6, pp.613-635.

Day, R. A. (1989), "The origins of the scientific paper: the IMRaD format". J Am Med Writers Assoc, Vol. 4 No. 2, pp.16-18.

de Kervenoael, R., Hasan, R., Schwob, A. and Goh, E., 2020, "Leveraging human-robot interaction in hospitality services: Incorporating the role of perceived value, empathy, and information sharing into visitors' intentions to use social robots", Tourism Management, Vol. 78, p.104042.

Di Vaio, A. and Varriale, L., 2020c, "Blockchain technology in supply chain management for sustainable performance: Evidence from the airport industry", International Journal of Information Management, Vol. 52, p.102014.

Di Vaio, A., Boccia, F., Landriani, L. and Palladino, R., 2020a, "Artificial intelligence in the agri-food system: Rethinking sustainable business models in the COVID-19 scenario", Sustainability, Vol. 12 No. 12, p.4851.

Di Vaio, A., Palladino, R., Hassan, R. and Escobar, O., 2020b, “Artificial intelligence and business models in the sustainable development goals perspective: A systematic literature review", Journal of Business Research, Vol. 121, pp.283-314.

Di Vaio, A., Palladino, R., Pezzi, A. and Kalisz, D.E., 2021, “The role of digital innovation in knowledge management systems: A systematic literature review", Journal of Business Research, Vol. 123, pp.220-231.

Di Vaio, A., Syriopoulos, T., Alvino, F., \& Palladino, R. (2020d), "Integrated thinking and reporting towards sustainable business models: a concise bibliometric analysis", Meditari Accountancy Research. doi: 10.1108/MEDAR-12-2019-0641.

Di Vaio, A., \& Varriale, L. (2020), "SDGs and airport sustainable performance: Evidence from Italy on organisational, accounting and reporting practices through financial and nonfinancial disclosure", Journal of Cleaner Production, Vol. 249, p.119431.

Dwivedi, Y. K., Hughes, L., Ismagilova, E., Aarts, G., Coombs, C., Crick, T., ... \& Williams, M. D., 2021, “Artificial Intelligence (AI): Multidisciplinary perspectives on emerging 
challenges, opportunities, and agenda for research, practice and policy ", International Journal of Information Management, Vol. 57, p.101994.

Foroudi, P., Tabaghdehi, S.A.H. and Marvi, R., 2020, "The gloom of the COVID-19 shock in the hospitality industry: A study of consumer risk perception and adaptive belief in the dark cloud of a pandemic", International Journal of Hospitality Management, Vol. 92, p.102717.

Garrido-Moreno, A., García-Morales, V. J., \& Martín-Rojas, R. (2021), "Going beyond the curve: Strategic measures to recover hotel activity in times of COVID-19", International Journal of Hospitality Management, Vol. 96, p.102928.

Gössling, S., Scott, D. and Hall, C.M., 2020, "Pandemics, tourism and global change: a rapid assessment of COVID-19”, Journal of Sustainable Tourism, Vol. 29 No. 1, pp.1-20.

Gursoy, D. and Chi, C.G., 2020, "Effects of COVID-19 pandemic on hospitality industry: review of the current situations and a research agenda", Journal of Hospitality Marketing \& Management, Vol. 29 No. 5, pp.527-529.

Hall, G. M. (Ed.). (2012), How to write a paper, John Wiley \& Sons, United Kingdom

Huang, M.H. and Rust, R.T., 2020, "Engaged to a Robot? The Role of AI in Service”, Journal of Service Research, doi: 10.1177/1094670520902266.

Lastoe, S., 2020, "Luxury Swiss apartment-style hotel launches Covid-19 guest package", available at: https://edition.cnn.com/travel/article/swiss-hotel-covid-19package/index.html

Im, J., Kim, H., \& Miao, L. (2021), "CEO letters: Hospitality corporate narratives during the COVID-19 pandemic”, International journal of hospitality management, Vol. 92, p.102701.

Ivanov, S., \& Webster, C. (2019), "Conceptual framework of the use of robots, artificial intelligence and service automation in travel, tourism, and hospitality companies.", Ivanov, S. (Ed.), \& Webster, C. (Ed.), Robots, Artificial Intelligence, and Service Automation in Travel, Tourism and Hospitality, Emerald Publishing Limited, United Kingdom, pp.7-37.

Jiang, Y. and Wen, J., 2020, "Effects of COVID-19 on hotel marketing and management: a perspective article". International Journal of Contemporary Hospitality Management, Vol. 32 No. 8, pp.2563-2573.

Jones, P., \& Comfort, D. (2020), “The COVID-19 crisis and sustainability in the hospitality industry", International journal of contemporary hospitality management, Vol. 32 No. 10, pp.3037-3050.

Kim, S.S., Chun, H. and Lee, H., 2005, "The effects of SARS on the Korean hotel industry and measures to overcome the crisis: A case study of six Korean five-star hotels", Asia Pacific Journal of Tourism Research, Vol. 10 No. 4, pp.369-377. 
Kuo, C.M., Chen, L.C. and Tseng, C.Y. 2017, "Investigating an innovative service with hospitality robots", International Journal of Contemporary Hospitality Management, Vol. 29 No. 5, pp.1305-1321.

Lai, I. K. W., \& Wong, J. W. C. (2020), "Comparing crisis management practices in the hotel industry between initial and pandemic stages of COVID-19", International Journal of Contemporary Hospitality Management, Vol. 32 No. 10, pp.3135-3156.

Majeed, S. and Ramkissoon, H., 2020, "Health, Wellness, and Place Attachment During and Post Health Pandemics", Frontiers in Psychology, doi: 10.3389/fpsyg.2020.573220.

Mariani, M.M. and Perez Vega, R., 2020, "Beyond the hype: psychological mechanisms enabling the acceptance, adoption, and engagement with artificial intelligence technology in marketing", Psychology and Marketing.

Martín-Martín, A., Orduna-Malea, E., Thelwall, M. and López-Cózar, E.D., 2018, "Google Scholar, Web of Science, and Scopus: A systematic comparison of citations in 252 subject categories", Journal of Informetrics, Vol. 12 No. 4, pp.1160-1177.

McKercher, B. and Chon, K., 2004, "The over-reaction to SARS and the collapse of Asian tourism", Annals of tourism research, Vol. 31 No. 3, p.716.

Mizrachi, I. and Fuchs, G., 2016, "Should we cancel? An examination of risk handling in travel social media before visiting ebola-free destinations", Journal of Hospitality and Tourism Management, Vol. 28, pp.59-65.

Nguyen, D.N., Imamura, F. and Iuchi, K. 2017, "Public-private collaboration for disaster risk management: A case study of hotels in Matsushima, Japan", Tourism Management, Vol. 61, pp.129-140.

Novelli, M., Burgess, L. G., Jones, A., \& Ritchie, B. W. (2018), 'No Ebola... still doomed'The Ebola-induced tourism crisis", Annals of Tourism Research, Vol. 70, pp.76-87.

Park, H., Kline, S. F., Kim, J., Almanza, B. and Ma, J. 2019, "Does hotel cleanliness correlate with surfaces guests contact?", International Journal of Contemporary Hospitality Management, Vol. 31 No. 7, pp.2933-2950.

Park, S., 2020, "Multifaceted trust in tourism service robots", Annals of Tourism Research, Vol. 81, p.102888.

Pillai, S. G., Haldorai, K., Seo, W. S., \& Kim, W. G. (2021), “COVID-19 and hospitality 5.0: Redefining hospitality operations", International Journal of Hospitality Management, Vol. 94, p.102869.

Ritchie, B. (2008), "Tourism disaster planning and management: From response and recovery to reduction and readiness", Current issues in Tourism, Vol. 11 No. 4, pp.315-348.

Rogers, R.W., 1975, “A protection motivation theory of fear appeals and attitude change1", The journal of psychology, Vol. 91 No. 1, pp.93-114.

Seyitoğlu, F., \& Ivanov, S. (2020), “Service robots as a tool for physical distancing in tourism”, Current Issues in Tourism, doi: 10.1080/13683500.2020.1774518. 
Sharma, A., Shin, H., Santa-María, M. J., \& Nicolau, J. L. (2021), "HOTELS'COVID-19 innovation and performance", Annals of Tourism Research, Vol. 88, p.103180.

Sharma, R., Singh, G., Sharma, S., Jones, P., Kraus, S. and Dwivedi, Y.K. (2020), "Digital Health Innovation: Exploring Adoption of COVID-19 Digital Contact Tracing Apps", IEEE TEM, doi: 10.1109/TEM.2020.3019033.

Shin, H., \& Kang, J. (2020), "Reducing perceived health risk to attract hotel customers in the COVID-19 pandemic era: Focused on technology innovation for social distancing and cleanliness”, International Journal of Hospitality Management, Vol. 91, p.102664.

United Nations, 2004, "Living with Risk. A global review of disaster reduction initiatives. UNITED NATIONS. New York and Geneva, 2004 Version - Volume I", Available at: https://www.unisdr.org/files/657_lwr1.pdf

Wang, G., Zhang, Y., Zhao, J., Zhang, J. and Jiang, F. 2020, "Mitigate the effects of home confinement on children during the COVID-19 outbreak", The Lancet, Vol. 395 No. 10228, pp.945-947.

Wang, J. and Wu, X., 2018, "Top-down or outside-in? Culturally diverse approaches to hotel crisis planning", Journal of Hospitality and Tourism Management, Vol. 36, pp.76-84.

Wen, J., Kozak, M., Yang, S. and Liu, F., 2020, “COVID-19: potential effects on Chinese citizens' lifestyle and travel”, Tourism Review, doi: 10.1108/TR-03-2020-0110

WHO, 2020, "COVID-19 management in hotels and other entities of the accommodation sector”, available at: https://apps.who.int/iris/handle/10665/333992

World Economic Forum (2020), "Here's what travelling could be like after COVID-19", available at: https://www.weforum.org/agenda/2020/05/this-is-what-travelling-willbe-like-after-covid-19/

Zemke, D.M.V., Neal, J., Shoemaker, S. and Kirsch, K. 2015, "Hotel cleanliness: Will guests pay for enhanced disinfection?", International Journal of Contemporary Hospitality Management, Vol 27 No. 4, pp.690-710.

Zeng, Z., Chen, P.J. and Lew, A.A., 2020, "From high-touch to high-tech: COVID-19 drives robotics adoption", Tourism Geographies, Vol. 22 No. 3, pp.724-734.

Zenker, S., \& Kock, F. (2020), “The coronavirus pandemic-A critical discussion of a tourism research agenda", Tourism management, Vol. 81, p.104164.

Zhong, L., Sun, S., Law, R. and Zhang, X., 2020, “Impact of robot hotel service on consumers' purchase intention: a control experiment", Asia Pacific Journal of Tourism Research, Vol. 25 No. 7, pp.780-798. 